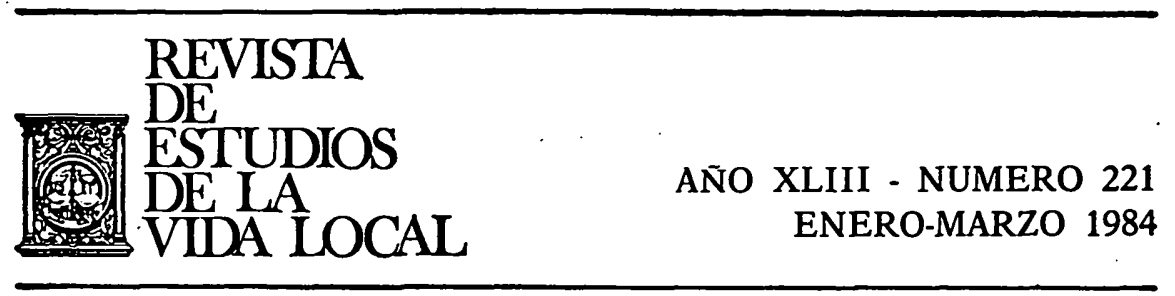

\title{
sumario
}



Págs.

Sebastian Martin-Retortillo: Perspectivas de la Administración pública $\ldots \ldots \ldots \ldots \ldots \ldots \ldots$

Miguel SÁNCHez Morón: Elementos de la participación ciu-

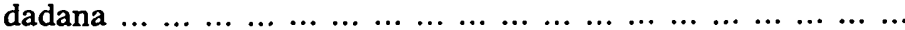

Santiago ANglada Gotor: Junta de Andalucía y Diputaciones Provinciales: Articulación de servicios periféricos $\ldots \ldots \ldots \ldots \ldots$

A. Delorenzo Neto: El sentido de la Administración municipal moderna. La reestructuración urbana de São Paulo $\begin{array}{llllllllllllllllllll}(\text { Brasil) } & \ldots & \ldots & \ldots & \ldots & \ldots & \ldots & \ldots & \ldots & \ldots & \ldots & \ldots & \ldots & \ldots & \ldots & \ldots & \ldots & \ldots & \ldots\end{array}$

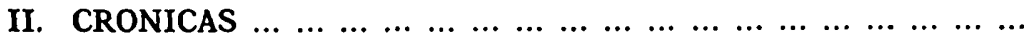

Fernando López Ramón: Crónica de la Semana de Estudios sobre la Constitución y la Administración Local ... ... ... ... ...

III. $\begin{array}{llllllllllllllllllll} & \text { ESTADISTICA } & \ldots & \ldots & \ldots & \ldots & \ldots & \ldots & \ldots & \ldots & \ldots & \ldots & \ldots & \ldots & \ldots & \ldots & \ldots & \ldots\end{array}$

IGNACIO BALlESTER Ros: El equipamiento y otras características de los hogares en las Comunidades Autónomas ... $\ldots \ldots \ldots$



1. Comentarios monográficos $\ldots \ldots \ldots \ldots$

Leopoldo Tolívar Alas: Estado-Corporaciones locales en la re-

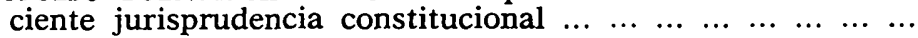

Nemesio Rodrfguez Moro: No es inconstitucional la Ley que establece el límite de sesenta años para concursar a las plazas de Secretario, Interventor y Depositario de los Ayuntamientos de Madrid y Barcelona $\ldots \ldots \ldots \ldots \ldots$

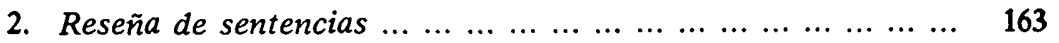

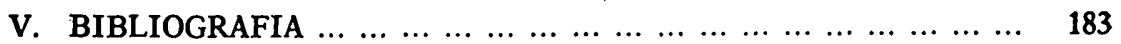

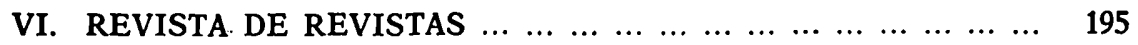


REVL-1984, núm. 221. SUMARIO 


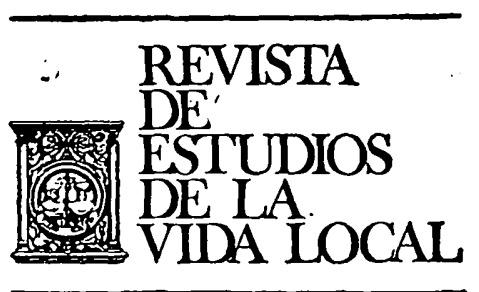

\section{SECCION DOCTRINAL}


REVL-1984, núm. 221. SUMARIO

REVL-1984, núm. 221. SUMARIO 